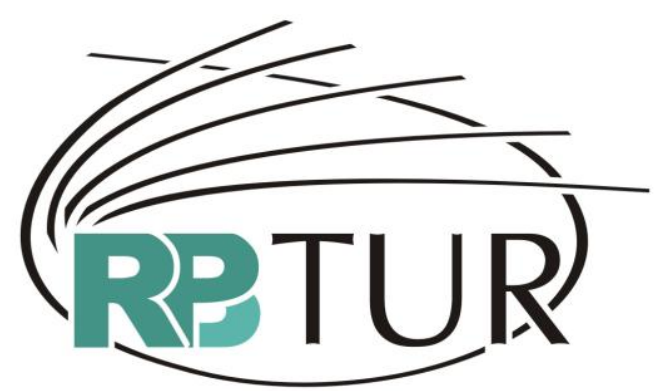

REVISTA BRASILEIRA DE PESQUISA EM TURISMO

\title{
PERFIL DOS TRABALHADORES DE COZINHA DA VIA GASTRONÔMICA DE COQUEIROS E NOTAS SOBRE A QUALIFICAÇÃO PROFISSIONAL NO SETOR DE ALIMENTOS E BEBIDAS EM FLORIANÓPOLIS/SC
}

\section{PROFILE OF WORKERS IN THE CUISINE OF THE COQUEIROS GASTRONOMIC WAY AND NOTES ABOUT THE QUALIFICATION IN THE FOOD AND BEVERAGE SECTOR IN FLORIANÓPOLIS (SANTA CATARINA, BRAZIL)}

\section{PERFIL DE LOS TRABAJADORES DE LA COCINA DE LA VIA GASTRONÓMICA DE COQUEIROS Y NOTAS SOBRE LA CALIFICACIÓN PROFESIONAL EN EL SECTOR DE ALIMENTOS Y BEBIDAS EN FLORIANOPOLIS (SANTA CATARINA, BRASIL)}

Adriana Terezinha das Chagas Assunção ${ }^{1}$

Fernando Goulart Rocha ${ }^{2}$ Liz Cristina Camargo Ribas ${ }^{3}$

Resumo: Florianópolis, capital do estado de Santa Catarina, é considerada uma cidade brasileira de relevância turística. Com o objetivo de levantar dados sobre a qualificação dos profissionais do setor de alimentos e bebidas, realizou-se uma caracterização dos trabalhadores de cozinha de uma via gastronômica específica da cidade, localizada no bairro de Coqueiros e adjacências. Para tanto, utilizou-se um questionário aplicado por meio de entrevista estruturada com 39 trabalhadores de 15 estabelecimentos. O perfil dos trabalhadores da Via Gastronômica de Coqueiros atestou a falta de exigência de escolaridade e de qualificação profissional na

1 Técnica em Cozinha pelo Instituto Federal de Santa Catarina, Campus Florianópolis Continente. Email: lizribas@ifsc.edu.br

2 Doutor em Geografia. Professor de Ciências Humanas do IFSC, Campus Florianópolis Continente. Email: fernandogr@ifsc.edu.br

${ }^{3}$ Mestre em Biotecnologia. Professora de Educação Ambiental do IFSC, Campus Florianópolis Continente. Email: lizribas@ifsc.edu.br 
contratação pelo empresariado, pequena especialização de funções de serviço e elevada rotatividade da mão-de-obra empregada.

Palavras-chave: Educação Profissional. Trabalhadores. Cozinha. Setor de Alimentos e Bebidas.

Abstract: This paper aimed at collecting data about the qualifications for professionals from the food and beverage sector in Florianópolis, the capital of Santa Catarina State, considered an important Brazilian city of tourism. Thus, a characterization of cuisine employees of a gastronomic way located in the neighborhood of Coqueiros and vicinity was carried out. Questionnaires have been applied through a structured interview with 39 workers from 15 establishments. The profile of the employees of the Coqueiros Gastronomic Way pointed to a lack of demand for schooling and professional qualification by entrepreneurs who hire the professionals. The little specialized functions for service and high turnover of staff employed have also been identified.

Keywords: Professional Education. Workers. Cuisine. Food and Beverage Sector.

Resumen: Florianópolis, capital del Estado de Santa Catarina, Brasil es considerada una ciudad con relevancia turística. Con el objetivo de obtener datos sobre la calificación de los profesionales del sector de alimentos y bebidas, se procedió a la caracterización de los trabajadores de cocina de una via gastronómica específica de la ciudad, localizada en el barrio de Coqueiros y alrededores. Para ello, se utilizó un cuestionario aplicado mediante entrevista estructurada, con 39 trabajadores de 15 establecimientos. El perfil de los trabajadores de la Via Gastronómica de Coqueiros reveló que, por parte de los empresarios, falta exigencia de escolaridad y de calificación profesional en el momento de contratar y reveló también poca especialización de funciones de servicio y alto índice de rotatividad en la mano de obra.

Palabras clave: Turismo y Gastronomia. Educación Profesional. Trabajadores de la Cocina. Sector de Alimentos y Bebidas.

\section{Introdução}

No Brasil, é crescente o número de pessoas que fazem refeições fora do domićlio (IBGE, 2004). Entretanto, questões relacionadas ao mercado de trabalho do setor de A\&B (Alimentos e Bebidas), tais como rotatividade de funcionários, polivalência de funções na empresa e baixa qualificação profissional, são citadas como dificuldades gerenciais que contribuem para a má qualidade nos serviços de alimentação, pois dificultam o desenvolvimento satisfatório do processo produtivo (SALAY, 2007).

De acordo com Davis (2003), a brigada de trabalho de um restaurante deve estar preparada para lidar com seus potenciais consumidores, ter 
atributos pessoais e conduta profissional, além de ater-se a uma série de técnicas e regras de serviço. Nessa direção, a qualificação profissional pode ser avaliada de acordo com competências, habilidades e conhecimentos técnicos dos trabalhadores, especialmente ligados ao saber-fazer, tais como: seleção de matérias-primas e das estratégias de comercialização da produção, domínio das tecnologias de preparo dos alimentos e execução de serviços de salão e de bebidas.

Além disso, espera-se do trabalhador em restaurantes uma conduta profissional que envolva atitudes como responsabilidade, segurança, postura e cortesia. Para tanto, a qualificação profissional é essencial, estando atrelada ao sistema educacional existente no país, ou seja, daquilo que as instituições de ensino e empresas fazem em prol da educação das pessoas a fim de transformá-las em profissionais capacitadas para atender, através do seu trabalho, às suas próprias aspirações, às dos empresários e às da população (CASTELLI, 2003).

Florianópolis, capital do Estado de Santa Catarina, é considerada uma cidade turística de relevância nacional. A partir dos anos oitenta, o fenômeno turístico na cidade se consolidou como atividade econômica, gerando na Ilha de Santa Catarina e no seu entorno uma série de modificações estruturais voltadas para a promoção de tal atividade - entre as quais a abertura de hotéis e restaurantes (OURIQUES, 1998), com a conseqüente geração de empregos. De acordo com Kanitz (2005), um restaurante talvez represente ser, em termos de empregabilidade, o maior responsável pela geração de postos de trabalho no turismo.

A importância econômica do turismo em Florianópolis, principal responsável pela expansão dos segmentos de mercado voltados à alimentação fora do lar, como restaurantes, não corresponde de maneira geral, entretanto, à semelhante profissionalização do setor de $A \& B$ no município. Nesse sentido, levantamentos recentes têm apontado para uma significativa deficiência de qualificação dos trabalhadores desse segmento. 
Nesse contexto, o presente trabalho visa a fornecer dados sobre o perfil de qualificação profissional e apontar elementos para a caracterização dos profissionais do setor de $A \& B$ em Florianópolis. De acordo com uma pesquisa de mercado realizada pelo Instituto Federal de Santa Catarina em 2009 (IFSC, 2009), apenas $27 \%$ de funcionários do setor de $A \& B$ na microrregião de Florianópolis possuíam algum curso na área, sendo que entre os principais motivos levantados para a falta de qualificação foram a falta de tempo (47\%); a falta de interesse (21\%) e a falta de oferta (13\%).

Observa-se, assim, que o mercado regional de trabalho em $A \& B$ é caracterizado pela baixa profissionalização e significativa parcela de trabalhadores desinteressados em qualificar-se. Tal desinteresse é explicado, em parte, pelas condições desfavoráveis de ascensão e prestígio social associado aos ofícios inerentes à ocupação de emprego em bares e restaurantes na referida área de estudos. Por outro lado, a baixa profissionalização está relacionada, na maioria das vezes, aos insuficientes salários pagos aos trabalhadores do setor, o que resulta na admissão de qualquer um e a qualquer preço, com a conseqüente ausência de critérios na contratação: gerentes e proprietários de estabelecimentos selecionam-se frequentemente os que vendem sua força de trabalho pelo menor preço, não pela maior capacidade técnica.

\section{Localização da Área de Estudos}

A Via Gastronômica de Coqueiros, criada em 2006 a fim de promover bares e restaurantes do bairro, está localizada na área continental de Florianópolis, abrangendo áreas não apenas desse bairro, mas também de outros, tais como Abraão, Bom Abrigo e Itaguaçu - figura 1. Atualmente ela é anunciada como uma das principais rotas gastronômicas da capital catarinense, sendo freqüentada principalmente pela população residente e, em menor número, por turismo durante a temporada de verão. 

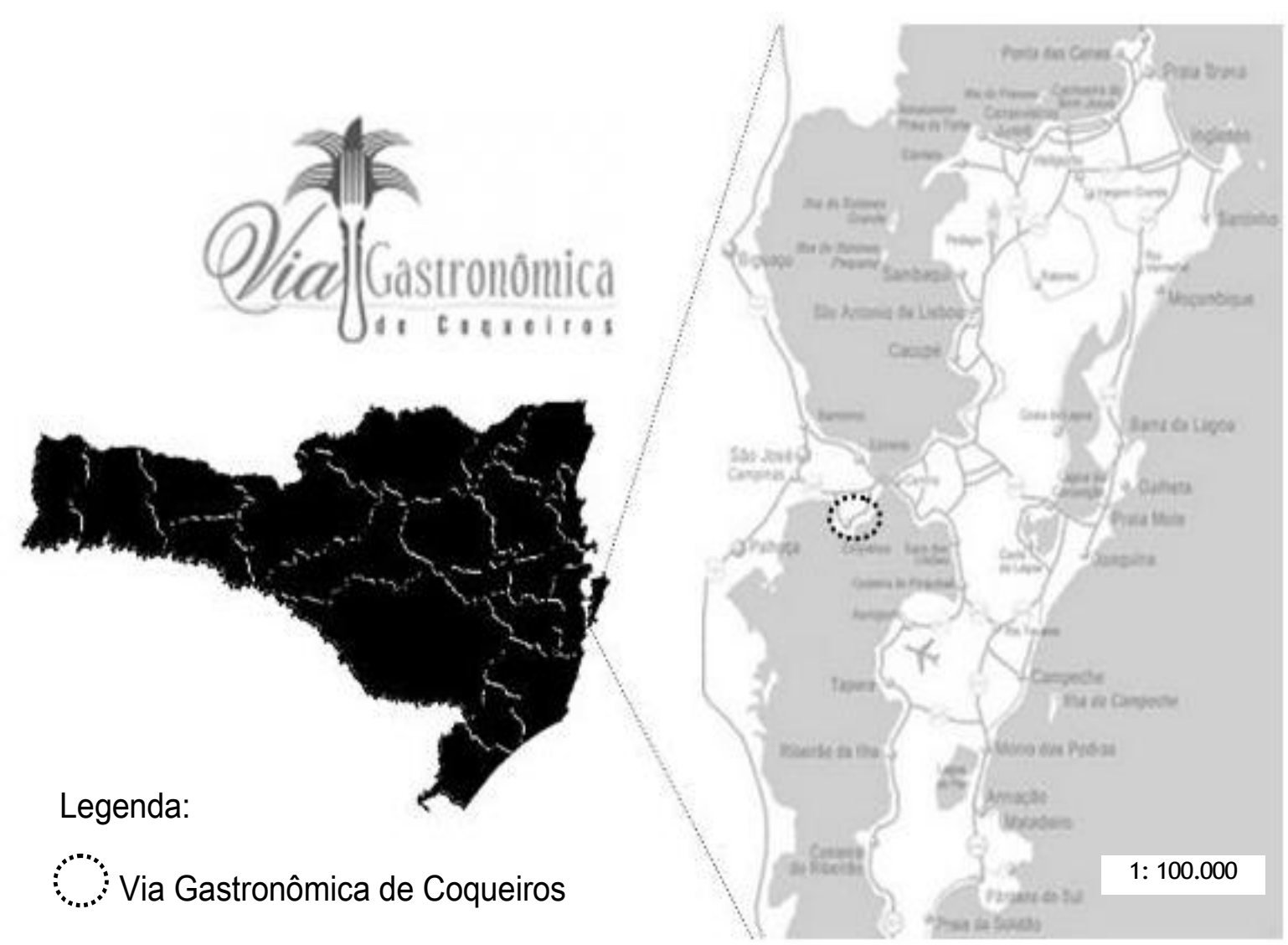

Figura 1 - Localização da Via Gastronômica de Coqueiros, município de Florianópolis (SC) Fonte: Associação Comercial e Industrial de Florianópolis, 2010.

\section{Método}

Apesar de reconhecida localmente pela diversidade de tipos de estabelecimentos (pizzarias, restaurantes, bares e lanchonetes), há uma carência de conhecimento sobre o perfil dos profissionais que trabalham na cozinha dos empreendimentos da Via Gastronômica de Coqueiros, especialmente no que diz respeito à qualificação. Para tanto, a caracterização do perfil dos trabalhadores do setor de cozinha da área analisada foi obtida por meio de um questionário aplicado através de uma entrevista estruturada. 0 instrumento de coleta de dados foi constituído por 14 questões de múltipla escolha, relacionadas ao levantamento do perfil da mão-de-obra local empregada na área de cozinha. Consideraram-se como mão-de-obra local os 
trabalhadores que residiam no bairro de Coqueiros, assim como em bairros adjacentes: Bom Abrigo, Abraão, Estreito e Itaguaçu.

A abordagem de coleta foi caracterizada pela aplicação do questionário aos trabalhadores do setor de 15 estabelecimentos selecionados para a pesquisa. Em 2009, tal número representava aproximadamente $50 \%$ dos estabelecimentos cadastrados na referida Via. A distribuição dos estabelecimentos e dos trabalhadores a serem pesquisados seguiu, por sua vez, o critério de aleatoriedade. Dessa maneira, ao todo foram aplicados 39 questionários com trabalhadores do setor durante o mês de novembro de 2009.

\section{Resultados e Discussão}

Avaliando-se o perfil dos trabalhadores verificou-se que a porcentagem de trabalhadores naturais do estado de Santa Catarina (54\%) é praticamente equivalente ao percentual dos que nasceram em outros estados brasileiros $(46 \%)$. Esse fato sugere a possível migração desse tipo de mão-de-obra das demais regiões do país para Florianópolis, em busca de oportunidades de emprego e melhores condições de vida. Entretanto, apesar do emprego, não se pode afirmar que tal mão-de-obra possui algum tipo de especialização na área de atuação, menos ainda que esses trabalhadores desfrutem de alguma ascensão social a partir do ofício que exercem. Pelo contrário, prevalece a condição do trabalho de auxiliar de cozinha como subemprego, freqüentemente mal remunerado, associado à falta de oferta de oportunidades, resultante da baixa escolaridade e qualificação profissional.

Convém notar, nesse sentido, que um retrato do setor levantado pela Pesquisa Nacional de Amostra por Domicílio (PNAD) de 1999, revelou que os trabalhadores de bares e restaurantes tinham em média 35 anos de idade, menos de sete anos de estudo, cumpriam jornadas de trabalho de 48 horas semanais e recebiam cerca de 2,5 salários mínimos mensais. Tratam-se, 
portanto, de trabalhadores adultos, com certa experiência no mercado de trabalho, mas, em geral, pouco escolarizados. Em decorrência disso, infere-se que a baixa escolaridade repercute em um mercado de mão-de-obra em serviços de alimentação pouco especializada, composta por trabalhadores que se sujeitam a trabalhar por salários modestos e a cumprir jornadas muitas vezes além da regulamentada.

Na microrregião de Florianópolis, a pesquisa realizada pelo IF-SC em 2009, sobre o mercado varejista de serviços de alimentação, apontou para o fato de que apenas $27 \%$ dos trabalhadores dessa área profissional são qualificados. Além disso, 63\% deles possuíam escolaridade menor que o ensino médio. Na área de estudos, o grau de escolaridade é ainda menor, pois aproximadamente $77 \%$ dos entrevistados não concluíram a referida etapa de estudos: $28 \%$ possuem ensino fundamental incompleto; 26\% apresentam ensino fundamental e $23 \%$ ensino médio incompleto. Apenas $13 \%$ dos trabalhadores declararam ter completado o ensino médio e $2 \%$ ensino superior, enquanto $8 \%$ iniciaram um curso de graduação, embora não 0 tenham concluíram. Dessa maneira, para o trabalho no setor de cozinha da Via - e provavelmente em Florianópolis como um todo, especialmente na função de auxiliar de cozinha - conclui-se que não é requisitada uma elevada escolaridade ou qualificação específica na área, a não ser cursos obrigatórios de higiene e manipulação de alimentos.

Em relação aos salários pagos, ainda de acordo com a pesquisa do IF-SC, $59 \%$ dos trabalhadores do setor de $A \& B$ na microrregião de Florianópolis recebiam mensalmente, em março de 2009, até um salário mínimo e meio, e $83 \%$ deles até 2,5 salários mínimos. Sobre a questão, reportagem publicada recentemente pelo Diário Catarinense, jornal impresso de circulação estadual, mostrou que dentre as áreas de maior recrutamento para emprego está justamente o segmento de serviços de alimentação. Contudo, ele é a que pior remunera. Na Via Gastronômica de Coqueiros, não é diferente. Entre os 
ISSN: $1982-6125$

cozinheiros entrevistados, 66\% afirmaram receber entre $\mathrm{R} \$ 501,00$ (quinhentos e um reais) e $\mathrm{R} \$ 1.000,00$ (um mil reais), conforme figura 2:

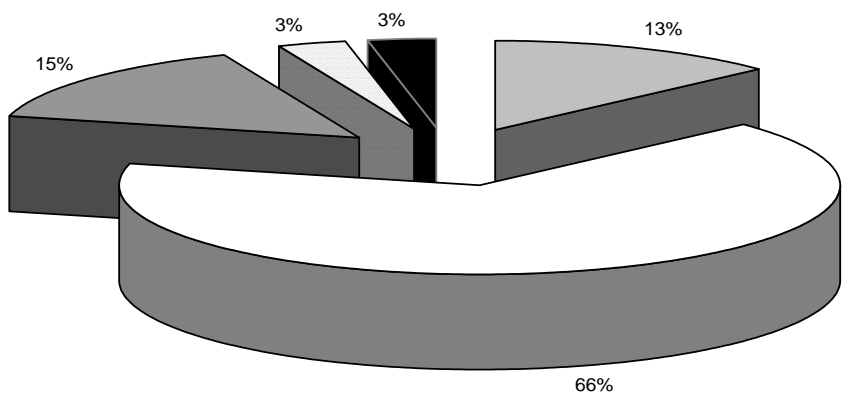

$\square$ Até $R \$ 500,00$

$\square R \$ 501,00$ a $R \$ 1.000,00 \quad \square R \$ 1.001,00$ a $R \$ 2.000,00$

$\square R \$ 2.001,00$ a $R \$ 3.000,00$

- Não respondeu

Figura 2 - Rendimento mensal dos trabalhadores do setor de cozinha da Via Gastronômica de Coqueiros, Florianópolis-SC, em 2009 Fonte: elaborado pelos autores.

Tem-se, portanto, que muitos dos migrantes acabam ocupando postos de trabalho pouco cobiçados no setor de alimentação, pois, até o momento, não se tem reparado maior interesse do empresariado local em arcar com custos mais elevados na contratação de um trabalhador melhor qualificado para esse tipo de serviço. Evidentemente que essa condição de desprofissionalização tem prejudicado a valorização dos trabalhadores especializados e que procuram atuar na área, haja vista que o auxiliar de cozinha ou mesmo o garçom, não qualificados, se submetem com frequência às mais precárias condições de emprego e remuneração.

Analisando-se a função exercida pelos profissionais do setor de cozinha da Via, observou-se que a maioria (69\%) exerce a função de auxiliar de cozinha, seguida pela função de cozinheiro (23\%) e chef de cozinha (8\%). Considerando as porcentagens encontradas, a estrutura hierárquica das 
ISSN: $1982-6125$

cozinhas brasileiras e o piso salarial por função no setor de $A \& B$, constatou-se o esperado: a ocorrência de mais auxiliares que cozinheiros e chefs de cozinha na Via estudada.

Por outro lado, apesar da remuneração não elevada, 74\% dos trabalhadores não possuem renda complementar, ou seja, a renda dos pesquisados é proveniente, em sua maioria, unicamente dos salários recebidos nos estabelecimentos pesquisados. Isso pode não ser um reflexo da falta de necessidade de renda complementar, mas em função da carga horária de trabalho requisitada pelos estabelecimentos. De acordo com a figura 3, nota-se que $71 \%$ dos questionados trabalham até oito horas diárias, enquanto $18 \%$ deles trabalham nove horas ou mais.

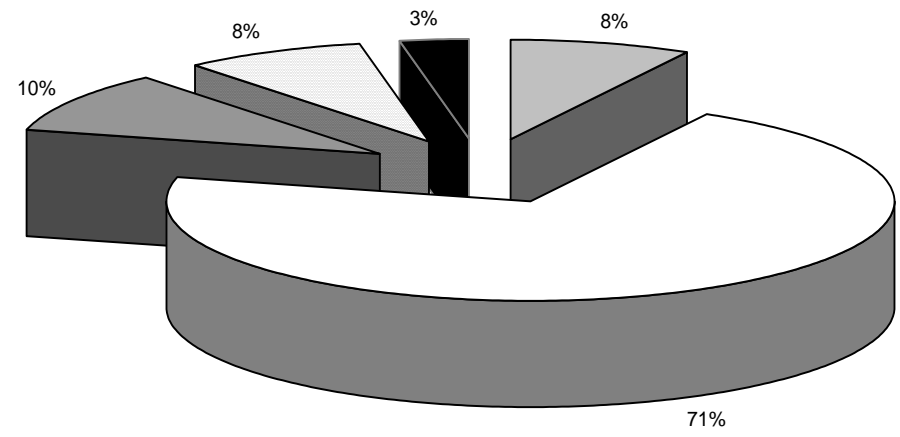

$\square$ Até 6 horas $\square$ Até 8 horas $\square$ Até 9 horas $\square 10$ horas ou mais $\square$ Não respondeu

Figura 3 - Horas-dia de trabalho dos empregados do setor de cozinha da Via Gastronômica de Coqueiros Florianópolis-SC, em 2009

Fonte: elaborado pelos autores.

Entretanto, possivelmente relacionada aos salários não elevados e à jornada de trabalho exaustiva, percebe-se uma elevada rotatividade de funcionários nos estabelecimentos pesquisados, pois o tempo de serviço dos 
ISSN: $1982-6125$

profissionais no estabelecimento atual de trabalho, em sua maioria (63\%), é inferior a 1 ano, conforme figura 4:

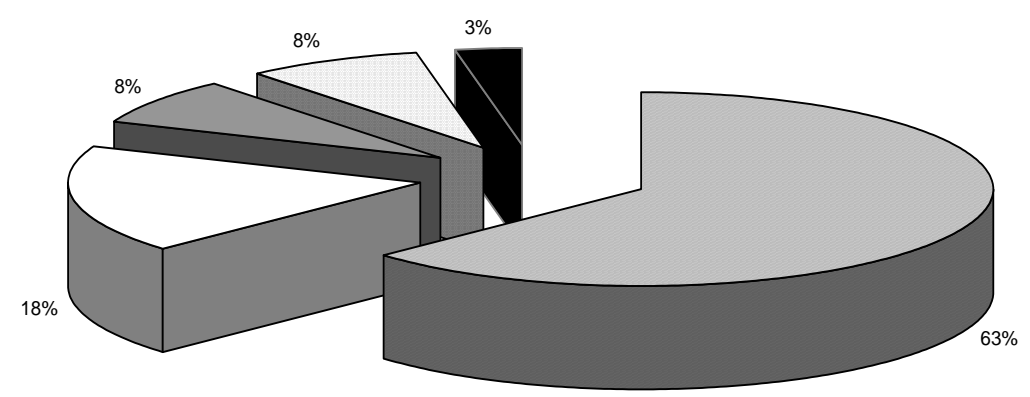

$\square$ Até 1 ano $\square$ De 1 a 3 anos $\quad \square$ De 3 a 5 anos $\quad \square$ De 5 a 10 anos Mais de 10 anos

Figura 4 - Tempo de trabalho no estabelecimento atual dos trabalhadores do setor de cozinha da Via Gastronômica de Coqueiros, Florianópolis-SC, em 2009 Fonte: elaborado pelos autores.

Segundo Shapiro (2007), em supermercados, bares, lanchonetes, pequenos restaurantes e congêneres, a média de tempo que os empregados permanecem é de seis meses a um ano. Entre os problemas apontados para a rotatividade podem ser citados: a elevada carga-horária (que inclui domingos e feriados), a falta de planejamento de cargos e salários, assim como a baixa remuneração em relação ao mercado de maneira geral. Todos esses entraves podem explicar a reduzida permanência dos trabalhadores nos estabelecimentos da Via estudada. A rotatividade de funcionários também foi verificada na pesquisa de mercado realizada na microrregião de Florianópolis: $45 \%$ dos entrevistados atuavam há menos de 1 ano no setor de $A \& B$, e 76\% há menos de 3 (IFSC, 2009). Por outro lado, apenas 12\% dos trabalhadores estão há mais de 7 anos na referida área profissional. 
A rotatividade de funcionários, porém, não significa que o setor de $A \& B$ seja caracterizado pela permanente requisição de trabalhadores novos. Nesse contexto, analisando-se o tempo total de serviço dos investigados, observouse que apenas $23 \%$ estão no setor há menos de 1 ano. Por outro lado, $49 \%$ estão na profissão há mais de 5 anos e 26\% há mais de 10 . Dessa maneira, os resultados demonstram que, na Via, ocorre elevada rotatividade dos funcionários entre os estabelecimentos, muito embora, sejam esses trabalhadores frequentemente já trabalhadores do setor.

Por sua vez, aproximadamente $60 \%$ dos trabalhadores investigados residem próximo à Via Gastronômica de Coqueiros. O emprego de mão-deobra local no turismo é extremamente positivo, o qual pode proporcionar um desenvolvimento social expressivo. Contudo, o dado encontrado não pode ser interpretado como emprego de mão-de-obra local stricto sensu, considerando o fato de muitos trabalhadores trocarem de endereço para residirem próximo ao local de trabalho e assim reduzirem despesas com transporte. Além disso, algumas vezes a exigência do empregador por trabalhadores que residam próximo ao estabelecimento é um dos motivos para a transferência do local de moradia do trabalhador.

Dos trabalhadores questionados, 54\% são mulheres e 46\% homens, o que demonstra certa equivalência na empregabilidade de ambos os gêneros. De acordo com a Pesquisa Nacional de Amostra de Domicílio (PNAD), no Brasil houve um aumento da participação das mulheres no mercado de trabalho, que passou de 42\%, em 1998, para 47,2\% em 2008 (IBGE, 2009). As porcentagens encontradas no presente trabalho corroboram com os dados apresentados pela PNAD.

Em relação à cor, $59 \%$ se autodeclararam brancos, seguidos por $18 \%$ pardos e 15\% negros. Esses índices demonstram que, somados, negros e pardos representam 33\% dos indivíduos questionados. Por outro lado, segundo a Síntese de Indicadores Sociais (SIS) de 2009, publicada pelo IBGE, o total de negros e pardos em Santa Catarina não ultrapassa $12,6 \%$ da população. A 
porcentagem encontrada na Via Gastronômica de Coqueiros pode assim representar a inclusão social desse grupo, marginalizada por muitos anos ou, contrariamente, ser um indicativo da sua própria marginalização, uma vez que os salários são relativamente baixos e não há maiores exigências de escolaridade no momento da contratação. Tal dado pode ser sustentando pelas diferenças nacionais encontradas nos rendimentos de negros e pardos em relação aos brancos, que são consideravelmente expressivas (IBGE, 2009).

Analisando-se a faixa etária dos trabalhadores empregados, verificou-se que a maioria apresenta idade entre 30 e 50 anos (46\%), sendo que a maior parte deles informou que trabalha na área por vocação (63\%), seguida da necessidade ( $31 \%$ ) e da falta de opção (6\%). Vocação, nesse caso, coloca-se com freqüência como discurso-comum para justificar a falta de oportunidades e conformar-se com a exaustão da rotina e jornada de trabalho a que esses trabalhadores estão submetidos. A vocação está associada à predestinação divina e, portanto, não pode ser questionada, assim como o próprio trabalho (WEBER,1996). Nesse contexto, o discurso burguês da vocação se coloca bastante eficaz a fim de justificar a condição de patrões e empregados e alentar os trabalhadores sobre as razões da diferenciação social.

$\mathrm{Na}$ avaliação da qualificação profissional, 67\% dos trabalhadores de cozinha da Via afirmaram que realizaram algum tipo de curso para a função que exercem. Dos trabalhadores que responderam ter qualificação na área, $51 \%$ têm curso na área de higiene e manipulação de alimentos, enquanto $21 \%$ realizaram cursos relacionados à área de cozinha, 2\% em panificação, 5\% em confeitaria e 7\% em serviços de bar e restaurante. Além desses, 14\% dos entrevistados realizaram outros cursos profissionalizantes. Esses dados evidenciam uma maior qualificação, quando existente, na área de higiene e manipulação de alimentos, provavelmente por ser obrigatória a todos os manipuladores de alimentos de Florianópolis, conforme Lei Municipal $\mathrm{n}^{\circ} 5.980$ de 2002, e Decreto $n^{\circ} 2.064$ de 2003. 
Por sua vez, muitos dos cursos realizados em áreas específicas são geralmente os chamados "treinamentos em serviço", oferecidos pelo próprio empregador, por fornecedores de insumos para o estabelecimento, ou por terceiros. Tais cursos são principalmente ocasionais e pouco criteriosos em relação à profissionalização.

Porém, de acordo com Kanitz (2005), para ser um bom profissional da gastronomia e manter sua empregabilidade, devem ser respeitadas algumas características básicas, assim como devem ser constantemente aprimoradas na busca de um nível de excelência e profissionalismo individual e coletivo. Dessa forma, a qualificação técnica e profissional específica da área de alimentos e bebidas necessita ser fortalecida na Via.

Segundo Heide (2005) e Magneé (2005), o que cria entraves para o crescimento profissional é, muitas vezes, a falta de escolas profissionais. Para os autores, existe carência no Brasil de instituições voltadas à formação de profissionais do setor de cozinha, e, a maioria visa à formação do que se conhece por chef de cozinha, uma função relativamente alta dentro da brigada. No entanto, em Florianópolis, inclusive próximo à Via Gastronômica analisada, há formação profissional gratuita na área de alimentos e bebidas, nas áreas técnicas voltadas a trabalhadores que não concluíram o nível fundamental. Apesar disso, questões como falta de expectativas em termos de elevação de renda aliadas à formação profissional e à elevada jornada de trabalho, especialmente noturna, parecem ser entraves para a qualificação desses trabalhadores. Acrescenta-se a essa situação a visão do empregador, ainda atrelada à idéia da não-necessidade de qualificação desse tipo de mão-deobra.

\section{Considerações Finais}

Os dados levantados sobre o perfil dos trabalhadores de cozinha da Via Gastronômica de Coqueiros permitem considerar que esses profissionais 
caracterizam-se pelos seguintes aspectos: a) escolaridade pouco elevada, sendo que a maioria não possui ensino médio completo; b) remuneração relativamente baixa - entre $\mathrm{R} \$ 501,00$ (quinhentos e um) e $\mathrm{R} \$ 1.000,00$ (um mil reais); c) jornada de trabalho em torno de 8 horas diárias; d) pouco tempo de trabalho no estabelecimento em que atua, apesar de considerável tempo de trabalho no setor de $A \& B$, fortalecendo a concepção de que se trata de uma área com alto grau de rotatividade de funcionários.

Além disso, o "trabalhador médio" da Via tem ainda idade entre 30 e 35 anos, ocupa a função de auxiliar de cozinha, justifica seu trabalho na área de alimentos e bebidas pela vocação, bem como se autodeclara branco. Não foi encontrado, entretanto, disparidades de gênero e de local de procedência (naturalidade) entre os trabalhadores da Via, sendo que a maior parte deles reside nas proximidades do estabelecimento em que trabalha.

Em relação à formação desses profissionais esperam-se, a partir dos indicadores levantados, ações mais eficazes no sentido de qualificar e elevar sua escolaridade visando principalmente à melhoria das suas condições de vida. Nesse sentido, almeja-se consolidar um mecanismo de acompanhamento do perfil dos trabalhadores da Via, de modo a monitorar a profissionalização da mão-de-obra empregada. Dessa maneira, novas pesquisas deverão ocorrer diante da necessidade de aumento do nível de escolaridade desses trabalhadores, bem como maior qualificação técnica, o que provavelmente possibilitará uma melhoria nos serviços prestados a turistas e à população residente no município de Florianópolis.

A seguir apresenta-se um quadro resumo das entrevistas realizadas na Via Gastronômica de Coqueiros sobre o perfil profissional dos trabalhadores do setor de cozinha, com base em 39 informantes, de 15 diferentes estabelecimentos, em 2009: 


\begin{tabular}{|c|c|}
\hline Tópicos & Resultados \\
\hline Naturalidade & $\begin{array}{l}54 \% \text { estado de Santa Catarina } \\
46 \% \text { outros estados brasileiros }\end{array}$ \\
\hline Grau de escolaridade & $\begin{array}{l}28 \% \text { ensino fundamental } \\
\text { incompleto } \\
26 \% \text { ensino fundamental completo } \\
23 \% \text { ensino médio incompleto } \\
8 \% \text { ensino superior incompleto } \\
2 \% \text { ensino superior completo }\end{array}$ \\
\hline $\begin{array}{ll}\text { Remuneração } & \text { no } \\
\text { estabelecimento } & \end{array}$ & $\begin{array}{l}13 \% \text { até } R \$ 500,00 \\
66 \% \text { de } R \$ 501,00 \text { a } R \$ 1.000,00 \\
15 \% \text { de } R \$ 1001,00 \text { a } R \$ 2.000,00 \\
3 \% \text { de } R \$ 2001,00 \text { a } R \$ 3.000,00 \\
3 \% \text { não responderam }\end{array}$ \\
\hline $\begin{array}{l}\text { Renda complementar } \\
\text { (empregado em mais de um } \\
\text { estabelecimento) }\end{array}$ & $\begin{array}{l}74 \% \text { não } \\
36 \% \text { sim }\end{array}$ \\
\hline Função no setor de cozinha & $\begin{array}{l}69 \% \text { auxiliar de cozinha } \\
23 \% \text { cozinheiro } \\
8 \% \text { Chef de cozinha }\end{array}$ \\
\hline Jornada de trabalho & $\begin{array}{l}8 \% \text { até } 6 \text { horas } \\
71 \% \text { até } 8 \text { horas } \\
10 \% \text { até } 9 \text { horas } \\
8 \% 10 \text { horas ou mais } \\
3 \% \text { não responderam }\end{array}$ \\
\hline $\begin{array}{l}\text { Tempo de serviço no atual } \\
\text { estabelecimento }\end{array}$ & $\begin{array}{l}63 \% \text { até } 1 \text { ano } \\
18 \% \text { mais de } 1 \text { e até } 3 \text { anos } \\
8 \% \text { mais de } 3 \text { e até } 5 \text { anos } \\
8 \% \text { mais de } 5 \text { e até } 10 \text { anos } \\
3 \% \text { mais de } 10 \text { anos }\end{array}$ \\
\hline $\begin{array}{l}\text { Tempo de serviço no setor de } \\
\text { alimentos e bebidas (A\&B) }\end{array}$ & $\begin{array}{l}23 \% \text { até } 1 \text { anos } \\
20 \% \text { mais de } 1 \text { e até } 3 \text { anos } \\
8 \% \text { mais de } 3 \text { e até } 5 \text { anos } \\
23 \% \text { mais de } 5 \text { e até } 10 \text { anos } \\
26 \% \text { mais de } 10 \text { anos }\end{array}$ \\
\hline $\begin{array}{l}\text { Domicílio próximo ao local de } \\
\text { trabalho }\end{array}$ & $\begin{array}{l}60 \% \text { sim } \\
40 \% \text { não }\end{array}$ \\
\hline Gênero & $\begin{array}{l}54 \% \text { homens } \\
46 \% \text { mulheres }\end{array}$ \\
\hline Cor autodeclarada & $\begin{array}{l}59 \% \text { brancos } \\
18 \% \text { pardos } \\
15 \% \text { negros } \\
2,5 \% \text { amarelos }\end{array}$ \\
\hline
\end{tabular}




\begin{tabular}{|c|c|}
\hline & $\begin{array}{l}2,5 \% \text { indígenas } \\
3 \% \text { não responderam }\end{array}$ \\
\hline Faixa etária & $\begin{array}{l}43 \% \text { menos de } 30 \text { anos } \\
46 \% \text { de } 30 \text { a } 50 \text { anos } \\
5,5 \% \text { mais de } 50 \text { anos } \\
5,5 \% \text { não responderam }\end{array}$ \\
\hline $\begin{array}{l}\text { Motivo pela escolha } \\
\text { profissional }\end{array}$ & $\begin{array}{l}63 \% \text { vocação } \\
31 \% \text { necessidade } \\
6 \% \text { falta de opção }\end{array}$ \\
\hline $\begin{array}{l}\text { Realização de cursos de } \\
\text { qualificação profissional }\end{array}$ & $\begin{array}{l}67 \% \text { sim } \\
33 \% \text { não }\end{array}$ \\
\hline $\begin{array}{l}\text { Cursos de qualificação } \\
\text { profissional realizados }\end{array}$ & $\begin{array}{l}21 \% \text { setor de cozinha } \\
7 \% \text { setor de serviços de } \\
\text { restaurante e bar } \\
5 \% \text { setor de confeitaria } \\
2 \% \text { setor de panificação } \\
51 \% \text { higiene e manipulação de } \\
\text { alimentos } \\
14 \% \text { outros } \\
\text { profissionalizantes }\end{array}$ \\
\hline
\end{tabular}

Fonte: pesquisa de campo.

\section{Agradecimentos}

Os pesquisadores agradecem à professora Nicole Pelaez e ao professor Vilson Goes, que colaboraram com a orientação e revisão do trabalho. Agradecem igualmente aos alunos do segundo semestre de 2009 do curso Técnico em Cozinha, Módulo 1, do Campus Florianópolis - Continente do IFSC, que auxiliaram na coleta de dados.

\section{Referências}

CASTELLI, G. Administração hoteleira. 9.ed. Caxias do Sul: EDUCS, 2003. 731p.

DAVIS, C. A. Manual de hospedagem: simplificando ações na hotelaria. 3. ed., Caxias do Sul: EDUCS, 2003. 
IBGE - Instituto Brasileiro de Geografia e Estatísticas. Pesquisa e orçamentos familiares. Rio de Janeiro: IBGE, 2004.

IBGE. Síntese de indicadores sociais 2009: uma análise das condições de vida da população brasileira. Rio de Janeiro (RJ): IBGE, 2009. 1 CD-ROM

IFSC. Relatório final da pesquisa de mercado com profissionais do setor de restaurantes, bares, lanchonetes, confeitarias e panificadoras, na região da Grande Florianópolis. Florianópolis: Centro Federal de Educação Tecnológica de Santa Catarina, 2009, mimeo.

KANITZ, H. G. O perfil do profissional de alimentos e bebidas: o chef de cozinha. Revista de Estudos Turísticos. São Paulo, 2006. Disponível em: < http://www.etur.com.br/conteudocompleto.asp?IDConteudo=7164>. Acesso em: setembro de 2010.

MAGNEÉ, H. Administração simplificada para pequenos e médios restaurantes. São Paulo: Livraria Varela, 2005. 129p.

OURIQUES, H. R. Turismo em Florianópolis: uma crítica à indústria pósmoderna. Florianópolis: Editora da UFSC, 1998. 150p.

SALAY, E. Consumo alimentar fora do domicilio: implicações para pesquisas em segurança alimentar e nutricional. Com Ciência: Revista eletrônica de jornalismo científico (2005). Disponível em: <http://www.comciencia.br>. Acesso em: março de 2010.

SHAPIRO, A. Alta rotatividade de funcionários. Profissão Atitude (2007). Disponível em: <http://profissaoatitude.blogspot.com>. Acesso em: abril de 2010.

WEBER, Max. A Ética protestante e o espírito do capitalismo. 11.ed. São Paulo: Pioneira, 1996.

Artigo recebido em setembro de 2010.

Aprovado para publicação em novembro de 2010. 